\title{
Differential recruitment of distinct amygdalar nuclei across appetitive associative learning
}

\author{
Sindy Cole, Daniel J. Powell, and Gorica D. Petrovich ${ }^{1}$ \\ Department of Psychology, Boston College, Chestnut Hill, Massachusetts 02467-3807, USA
}

\begin{abstract}
The amygdala is important for reward-associated learning, but how distinct cell groups within this heterogeneous structure are recruited during appetitive learning is unclear. Here we used Fos induction to map the functional amygdalar circuitry recruited during early and late training sessions of Pavlovian appetitive conditioning. We found that a number of distinct amygdalar nuclei were differentially recruited by tone-food pairings during the early and late stages of training, suggesting evidence of learning-induced plasticity. Notably, these selectively activated nuclei belong to dissociable subsystems that are well placed to simultaneously inform cortical (cognitive) processing and behavioral control during tone-food learning.
\end{abstract}

[Supplemental material is available for this article.]

The amygdala is critical for emotional learning and memory. The majority of evidence for this function initially came from studies of fear and aversive learning (Davis 2000; Paré et al. 2004; Gross and Canteras 2012; LeDoux 2012), but more recent studies show that the amygdala is also critical in reward-associated learning. The common mechanism underlying many reward paradigms is Pavlovian appetitive conditioning, where a neutral cue such as a tone (conditioned stimulus [CS]) is paired with food (unconditioned stimulus [US]). Through this training the CS acquires the ability to subsequently influence the motivation for both food seeking and consumption. For example, an appetitive CS can enhance instrumental responses (i.e., lever presses) previously associated with access to food (Estes 1948), and can stimulate eating in sated animals (Weingarten 1983). Even though this basic associative learning plays a critical role in guiding motivated behaviors, the neural substrates underlying the CS-US learning are largely unknown.

In appetitive preparations the focus has been on two large areas of the amygdala, the basolateral area (typically consisting of the basolateral, basomedial, and lateral nuclei) and the central nuclei. Interestingly, studies in laboratory animals and humans have consistently demonstrated dissociation in the function of these two regions in appetitive and reward tasks (Everitt et al. 2003). For example, the basolateral area is critically involved in cuepotentiated eating, enhancement of instrumental responses by an appetitive CS for the same food, second-order appetitive conditioning, and reinforcer devaluation (Hatfield et al. 1996; Holland et al. 2002; Setlow et al. 2002; Pickens et al. 2003; Corbit and Balleine 2005; Prévost et al. 2012). In contrast, the central nucleus is necessary for the inhibition of eating by an aversive cue, general enhancement of instrumental responses for food, conditioned orienting behavior, and conditioned approach to cues (Gallagher et al. 1990; Parkinson et al. 2000; Corbit and Balleine 2005; Petrovich et al. 2009; Prévost et al. 2012; but see Chang et al. 2012). Collectively, these studies strongly indicate different functional contributions for distinct amygdalar regions in appetitive and reward behaviors. Although important and informative, findings from these prior studies, due to the techniques employed, do not provide sufficient specificity in regard to particular cell groups

\footnotetext{
${ }^{1}$ Corresponding author
}

E-mail gorica.petrovich@bc.edu

Article is online at http://www.learnmem.org/cgi/doi/10.1101//m.031070.113. within these large amygdalar areas. Such specificity is crucial given the complexity of this telencephalic structure, which comprises distinct cell groups that form part of distinct neural networks (Swanson and Petrovich 1998).

To begin to define the critical circuitry underlying a CS-food association, here we used immunohistochemical detection of the immediate early gene $c$-fos protein (Fos) induction to examine functional activation of distinct amygdalar subnuclei across early and late stages of training. The results are critical for elucidating the mechanisms underlying such CS-food learning and its numerous behavioral sequelae.

Animals were perfused and brains collected following a training session where rats received eight presentations of a tone CS which co-terminated with delivery of food pellets (US) (two 45-mg pellets) distinct from their regular diet (group Paired). Control animals were perfused following a conditioning session with tone CS-only presentations (group Tone) or after delivery of the food US (16 pellets at once) in the home cage (group Food). Half of the animals were perfused after one training session (D1) while the other half were perfused following 10 training sessions (D10) (see Fig. 1A for experimental design and Supplemental Methods for details). Following training sessions one to nine, D10 Tone animals also received US delivery in their home cage. This was to equate them for prior experience with the food, but following the final training session they did not receive the US prior to perfusion. It is also important to note that D1 and D10 animals received identical training during these sessions, differing only in the number of training sessions received. This design allowed us to identify and directly compare amygdalar nuclei that were specifically recruited by CS-food pairings across different stages of learning.

On Day 1 there was significantly greater food-cup behavior (conditioned responding) to the tone during the final two CSs than during the first two CSs $\left(F_{(1,21)}=4.408, P<0.05\right)$ and this difference was significantly greater for the Paired group compared with Tone and Food animals $\left(F_{(1,21)}=7.816, P<0.05\right)$ (Fig. 1B). Follow-up tests confirmed that only Paired animals showed within-session appetitive learning. There were no differences between groups during the first two CSs ( $\left.P^{\prime} \mathrm{s}>0.05\right)$, but during the final two CSs Paired animals showed significantly greater CS-responding than Tone and Food animals $\left(F_{(1,21)}=12.589\right.$, $P<0.01)$ which did not differ $(P>0.05)$. Furthermore, while Paired animals showed an increase in CS-responding $\left(F_{(1,7)}=13\right.$, 
A

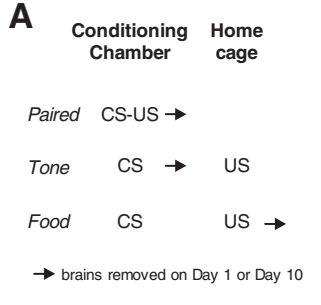

C

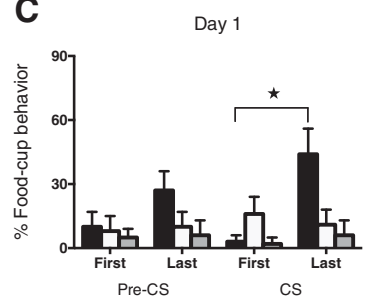

E

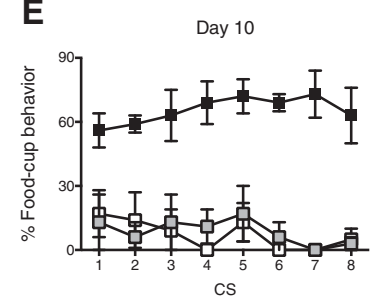

cs
B

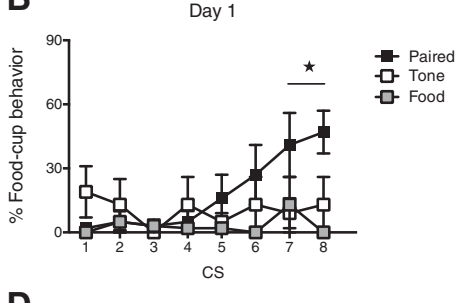

D Training

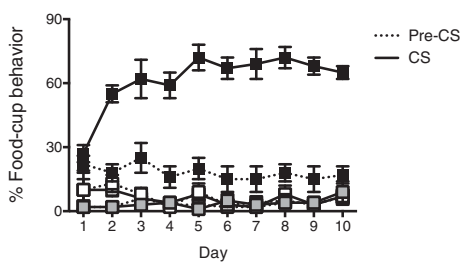

$\mathbf{F}$

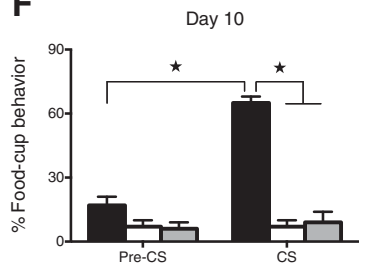

Figure 1. ( $A$ ) Experimental design. CS denotes presentation of a 10-sec, $75-\mathrm{dB}, 2-\mathrm{kHz}$ tone. US denotes delivery of two 45-mg food pellets. Each training session consisted of eight presentations of the appropriate stimuli. Animals received either $1 \mathrm{~d}$ or $10 \mathrm{~d}$ of training. (B) Mean ( \pm SEM) percentage of food-cup behavior across CS presentations during Day 1. Only Paired animals showed greater food-cup behavior to the tone during the final two CSs than during the first two CSs, confirming the acquisition of appetitive conditioning. (C) Mean ( \pm SEM) CS and pre-CS responding during the first two and last two CS presentations during Day 1. Paired animals demonstrated a significant increase in CS food-cup behavior, but not in pre-CS responding. (D) Mean ( \pm SEM) percentage of CS and pre-CS food-cup behavior across days of training. Paired animals showed an increase in CS responding across days of training, but not in pre-CS responding. ( $E$ ) Mean ( \pm SEM) percentage of foodcup behavior across CS presentations during Day 10. Only Paired animals showed consistently high food-cup behavior during CS presentations. $(F)$ Mean ( \pm SEM) percentage of CS and pre-CS food-cup behavior during Day 10. Paired animals showed significantly greater CS food-cup behavior overall compared with Tone and Food controls. Paired animals also exhibited significantly greater food-cup behavior during CS presentations than during the pre-CS periods, indicating that the learned appetitive behavior was specific to the CS. (*) $P<0.05$.

$P<0.01)$, they did not show such an increase in pre-CS responding $(P>0.05)$, confirming that the increase in food-cup behavior seen in Paired animals was specific to the CS (Fig. 1C).

Across days of training, D10 Paired animals showed greater CS-responding overall than Tone and Food animals $\left(F_{(1,20)}=\right.$ 208.869, $P<0.0001)$ which did not differ $(P>0.05)$. There was a significant interaction of this group effect with a linear trend across days $\left(F_{(1,20)}=7.963, P<0.05\right)$ indicating that Paired animals showed an increase in CS food-cup behavior across days of training. There was no such increase for pre-CS responding $(P$ 's $>0.05)$ (Fig. 1D).

During the Day 10 session Paired animals showed greater food-cup behavior overall than Tone and Food animals $\left(F_{(1,20)}=\right.$ 81.897, $P<0.0001)$ which did not differ $(P>0.05)$ (Fig. 1E). There was overall more food-cup behavior shown during the CS than the pre-CS periods $\left(F_{(1,20)}=72.459, P<0.0001\right)$ which was greater in Paired animals $\left(F_{(1,20)}=120.009, P<0.0001\right)$, indi-

cating that only D10 Paired animals expressed robust appetitive conditioning which was specific to the CS (Fig. 1F). The level of CS-responding seen in Paired animals was comparable to that in prior studies employing similar training procedures (e.g., Hatfield et al. 1996).

Fos induction was subsequently examined systematically in eight cell groups within the basolateral and central amygdalar regions (see Table 1 and Supplemental Methods for details). Counts of Fos-positive neurons were conducted bilaterally through the rostro-caudal extent of each area analyzed, summed for each rat, and then averaged for each group, resulting in a mean total of Fos-labeled neurons. In the following analyses, CS-US associated Fos induction refers to significant group differences in Fos expression so that group Paired was significantly greater than groups Tone and Food, which did not differ (Paired $>$ Tone $=$ Food). CS-associated Fos induction refers to significant group differences in Fos expression so that groups Paired and Tone were significantly greater than group Food (Paired $=$ Tone $>$ Food). Representative photomicrographs from D10 brains are displayed in Figure 2. The means of total counts of Fos induction in each cell group are shown in Figure 3.

The only cell group that showed CS-US associated Fos induction during D1 was the anterior basolateral nucleus (BLAa), and that pattern was maintained in D10. Thus, the BLAa demonstrated a unique profile of Fos induction, consistently showing CS-US associated Fos expression in both D1 and D10 (D1 $F_{(2,21)}=8.52$, $\left.P<0.01 ; \mathrm{D} 10 F_{(2,20)}=22.53, P<0.0001\right)$. The posterior basolateral nucleus (BLAp) initially showed CS-associated Fos $\left(F_{(2,21)}=\right.$ $7.82, P<0.01)$, suggesting that this region was initially activated by presentation of the CS and/or arousal associated with the conditioning chamber. Nevertheless, during D10 the BLAp showed significant CS-US associated Fos expression $\left(F_{(2,20)}=17.51, P<\right.$ $0.0001)$. The only other cell groups to show CS-US associated Fos induction during D10 were the medial and capsular parts of the central nucleus (CEAm and CEAc, respectively) (CEAm $F_{(2,20)}=7.55, P<0.01 ;$ CEAc $\left.F_{(2,20)}=8.37, P<0.01\right)$. In contrast to the BLAa and BLAp, however, there were no differences in Fos induction across conditions in CEAm or CEAc in D1 ( $P$ 's $>0.05)$.

The posterior basomedial nucleus (BMAp) consistently showed CS-associated Fos (D1 $F_{(2,21)}=10.55, \quad P<0.01 ;$ D10 $\left.F_{(2,20)}=11.02, \quad P<0.01\right)$. The anterior basomedial nucleus (BMAa) also showed CS-associated Fos, but only in D10 $\left(F_{(2,20)}=\right.$ $8.59, P<0.01)$. There were no group differences in D1 for BMAa $(P>0.05)$. In the lateral amygdalar nucleus (LA) and the lateral part of the central nucleus (CEAl) there were no significant differences in Fos induction between groups at any time ( $P$ 's $>0.05)$.

Here we examined functional activation of eight amygdalar cell groups across tone (CS)-food learning. First, we found that the BLAa was selectively and consistently recruited in animals receiving CS-food pairings. Paired animals showed greater numbers of Fos-positive neurons compared to both Tone and Food

Table 1. The rostro-caudal extent of each amygdalar region analyzed

\begin{tabular}{lccc}
\hline Cell group & Atlas levels & Number of sections & mm from bregma \\
\hline BLAa & $25-28$ & 8 & -1.53 to -2.45 \\
BLAp & $28-32$ & 10 & -2.45 to -3.90 \\
BMAa & $25-27$ & 6 & -1.53 to -2.00 \\
BMAp & $29-32$ & 8 & -2.85 to -3.90 \\
LA & $28-32$ & 10 & -2.45 to -3.90 \\
CEAm & $25-28$ & 8 & -1.53 to -2.45 \\
CEAC & $25-28$ & 8 & -1.53 to -2.45 \\
CEAI & $26-28$ & 6 & -1.78 to -2.45 \\
\hline
\end{tabular}

Atlas levels refer to the rat brain atlas of Swanson (2004). 

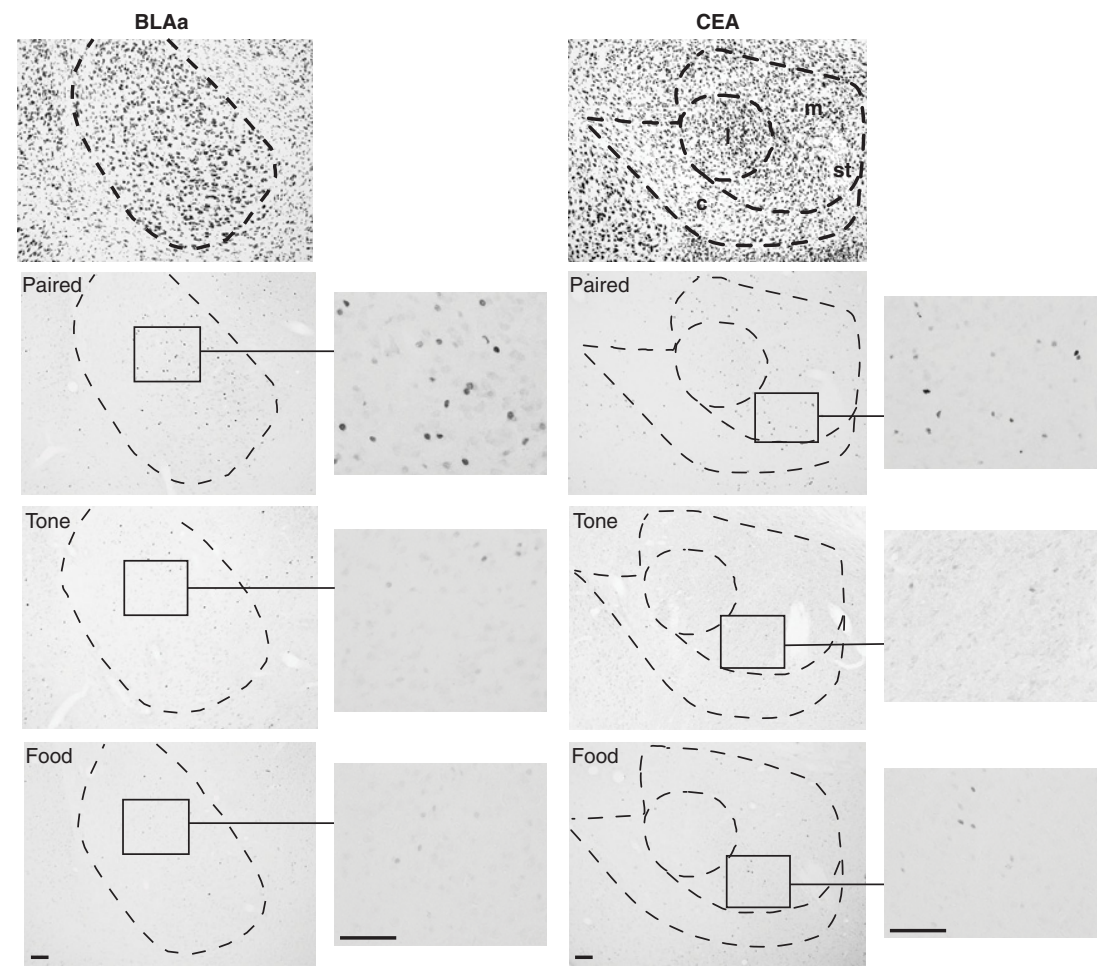

Figure 2. Representative photomicrographs of a thionin-stained section, and Fos induction (black nuclei) in the anterior part of the basolateral amygdalar nucleus (BLAa) (left) and the medial and capsular parts of the central amygdala (CEAm and CEAC, respectively) (right) following Day 10 training. (I) Lateral division of the central amygdala, (st) stria terminalis. Bar, $100 \mu \mathrm{m}$.

controls, which did not differ. This increase in Fos induction was apparent during both early (D1) and late (D10) training sessions. Second, we found that cell groups within both the basolateral and central regions were selectively recruited in the Paired group by the late training session. Specifically, brains from the Paired group showed greater Fos induction in the BLAp, CEAm, and CEAc. Third, we observed that nuclei were differentially recruited across early and late training sessions. Following the early training session we found significantly elevated Fos expression for both Paired and Tone groups in the BLAp and BMAp, but not in any CEA nuclei. This increase could be the result of a learning process (learning the tone-food association or habituating to the tonealone presentations), or simply due to the presence of the CS. Nevertheless, these data suggest that the BLAp and BMAp may act to detect the initial occurrence of biologically significant events. More importantly, after extensive training the CS-US associated Fos induction pattern was observed throughout a greater number of amygdalar nuclei than after initial training, suggesting evidence of learning-induced plasticity selectively within BLAp, CEAm, and CEAc.

The inclusion of the Tone and Food controls used here allows numerous alternate interpretations of the results to be ruled out. Specifically, the increases in Fos expression seen in Paired animals cannot be attributed to arousal associated with exposure to the tone itself, the conditioning chamber, transport, or handling, because Tone animals received equal exposure to all of these stimuli. Furthermore, the observed Fos induction in Paired animals is not simply due to the consumption of the food US, because the Food group consumed an identical quantity under the same fooddeprived state. The amount of food given to Paired and Food animals was small, but it was sufficiently motivating to support learning as evidenced by significant behavioral change in the
Paired animals. Furthermore, consumption of the food was sufficient to induce significant Fos expression. As clearly shown in Figure 3, in the CEAl the Food group actually expressed the most Fos of the three D1 groups (although there were no significant group differences), and in the LA induction was similarly robust as in the Paired and Tone groups. Thus, the groups used in the current study not only controlled for behavioral effects, but also were appropriately designed for Fos imaging and allowed identification of a critical subsystem that was selectively recruited during tone-food learning. It is worth noting that recent studies employing the Daun02 inactivation method have shown that Fos expression is causally linked with behavior (Koya et al. 2009; Bossert et al. 2011). Therefore, our findings suggest functional plasticity in distinct amygdalar nuclei specifically as a result of tone-food pairings.

The recruitment of cell groups in both the basolateral and central regions is of particular interest given the substantial evidence that they are structurally and functionally distinct. There is strong developmental, connectional, neurotransmitter, and functional support that the basolateral region is cortical, while in contrast the central region is a striatal structure (Swanson and Petrovich 1998). Additionally, connectional evidence clearly demonstrates that these nuclei operate within distinct neural networks. Furthermore, our finding that the BLAa was the only amygdalar cell group recruited consistently across CS-food training is of note, given that the BLAa is unique among amygdalar nuclei in its connectional pattern. It connects extensively with frontotemporal and striatal regions including pre-motor cortex and the dorsal striatum, areas typically not innervated by the amygdala, while it does not send direct projections to the classic amygdalar outputs such as the CEAm, hippocampal formation, bed nuclei of the stria terminalis, hypothalamus, or brainstem (Kita and Kitai 1990; McDonald 1998). On the other hand the CEAm is wellrecognized as the main amygdalar output to the autonomic and behavioral systems within the diencephalon and hindbrain through extensive direct and indirect pathways (Dong et al. 2001; Lee et al. 2005). Thus, here we found selective recruitment of two dissociable amygdalar subsystems that are well placed to simultaneously inform cortical (cognitive) processing and behavioral control.

While the BLAa and CEAm are well placed to function in parallel, the BLAa could also inform CEAm (and CEAc) through its connections with BLAp (Savander et al. 1995; Swanson and Petrovich 1998). It is therefore interesting to note that while only the BLAa was selectively recruited by the initial tone-food learning, its targets, the BLAp and indirectly the CEAm and CEAc, were selectively recruited following more extensive training. This is consistent with the suggestion that the basolateral area acts as the primary processor of emotional information, which through cooperation with other cortical regions results in the appropriate behavioral response (Schoenbaum et al. 1998; Piette et al. 2012). In line with this suggestion, it is evident that the mean numbers of Fos positive cells remained consistently 

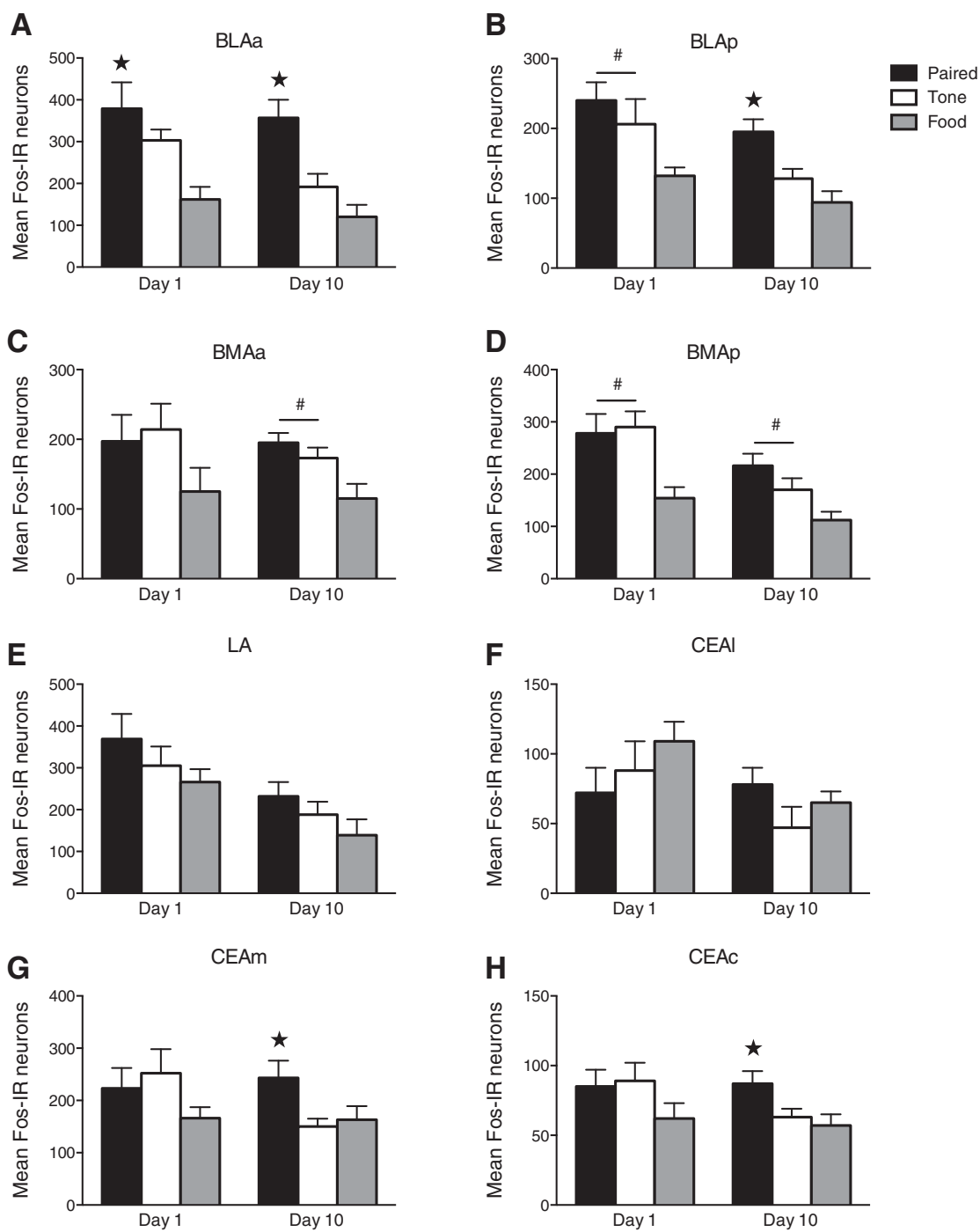

I Frontotemporal Systems

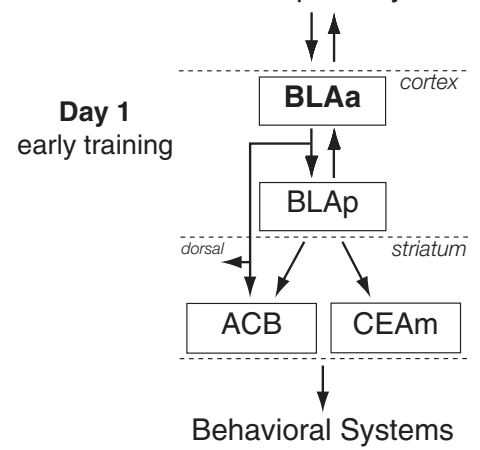

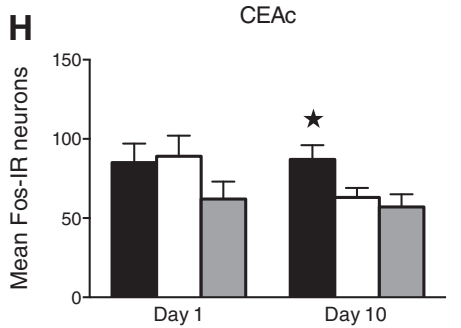

Frontotemporal Systems

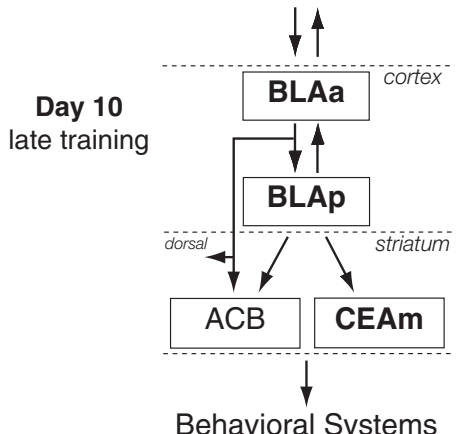

Behavioral Systems

Figure 3. $(A-H)$ Mean $\left( \pm\right.$ SEM) total counts of Fos-positive neurons in amygdalar cell groups. $\left.{ }^{*}\right) P<$ 0.05 comparing group Paired to groups Tone and Food. $(\#) P<0.05$ comparing groups Paired and Tone to group Food. (I) Schematic illustrates selective activation in distinct amygdalar cell groups across early and late CS-food learning. Bold text denotes selective CS-food associated Fos induction. Initial CS-food pairings (Day 1) are associated with selective activation of the BLAa, while CS-food pairings during a later training session (Day 10) are associated with activation of the BLAa and additional nuclei, the BLAp, CEAm (and CEAC). (ACB) nucleus accumbens, (BLAa) anterior basolateral amygdalar nucleus, (BLAp) posterior basolateral amygdalar nucleus, (BMAa) anterior basomedial amygdalar nucleus, (BMAp) posterior basomedial amygdalar nucleus, (CEAC) capsular central amygdalar nucleus, (CEAl) lateral central amygdalar nucleus, (CEAm) medial central amygdalar nucleus, (LA) lateral amygdalar nucleus.

high in the BLAa across D1 and D10 Paired groups (see Fig. 3A), which is particularly striking considering that Fos expression has been shown to reduce across both associative and nonassociative types of learning (Radulovic et al. 1998). Such an account would also explain why post-training lesions of the basolateral area have no effect on subsequent second-order appetitive conditioning (Setlow et al. 2002), or devaluation (Pickens et al. 2003). However, further studies are needed to determine whether, in fact, the same cells are activated across the course of training, and to define the specific pathways used to maintain the behavior.

This activation of both the basolateral and central areas of the amygdala during appetitive conditioning is in agreement with the well-documented role of these areas in aversive conditioning (LeDoux et al. 1990; Goosens and Maren 2001; Wilensky et al. 2006). Importantly, however, these data suggest that the exact nuclei implicated in these two forms of associative learning differ. In fear conditioning the LA is wellrecognized as a critical locus of plasticity for successful fear conditioning (Maren 2005; Sigurdsson et al. 2007). In contrast, here we did not find selective recruitment of this region during early or late stages of learning. Furthermore, Ciocchi et al. (2010) demonstrated dissociation in CEA function where CEAl and CEAm were critical for the acquisition and expression, respectively, of fear conditioning. In contrast, here we found functional activation in CEAm (but not CEAl) during D10, while previously Lee et al. $(2005,2010)$ showed that only CEAm activity increased with more CS-food pairings, and was sensitive to prior training history. Collectively, these results suggest that distinct amygdalar subsystems are critical in the two forms of associative learning.

In conclusion, we found selective recruitment of distinct amygdalar cell groups during CS-food learning. Specifically, during an early training session only the BLAa was recruited by CS-food pairings. In contrast, during an identical later training session a number of additional nuclei also showed CS-US associated Fos induction in addition to the BLAa. Importantly, these nuclei (BLAa, BLAp, CEAm, and CEAc) operate through dissociable circuitries, which suggests that during appetitive conditioning information about the CS-food association might be conveyed simultaneously via a distributed network to mediate different aspects of learning and the subsequent control of behavior (see Fig. 3I). 


\section{Acknowledgments}

This work was supported by The National Institute of Diabetes and Digestive and Kidney Diseases (NIDDK) (DK085721).

\section{References}

Bossert JM, Stern AL, Theberge FRM, Cifani C, Koya E, Hope BT, Shaham Y. 2011. Ventral medial prefrontal cortex neuronal ensembles mediate context-induced relapse to heroin. Nat Neurosci 14: $420-422$.

Chang SE, Wheeler DS, Holland PC. 2012. Effects of lesions of the amygdala central nucleus on autoshaped lever pressing. Brain Res 1450: 49-56.

Ciocchi S, Herry C, Grenier F, Wolff SB, Letzkus JJ, Vlachos I, Ehrlich I, Sprengel R, Deisseroth K, Stadler MB, et al. 2010. Encoding of conditioned fear in central amygdala inhibitory circuits. Nature 468: $277-282$.

Corbit LH, Balleine BW. 2005. Double dissociation of basolateral and central amygdala lesions on the general and outcome-specific forms of Pavlovian-instrumental transfer. J Neurosci 25: 962-970.

Davis M. 2000. The role of the amygdala in conditioned and unconditioned fear and anxiety. In The amygdala (ed. JP Aggleton), Vol. 2, pp. 213-288. Oxford University Press, Oxford, UK.

Dong HW, Petrovich GD, Swanson LW. 2001. Topography of projections from amygdala to bed nuclei of the stria terminalis. Brain Res Brain Res Rev 38: 192-246.

Estes WK. 1948. Discriminative conditioning; effects of a Pavlovian conditioned stimulus upon a subsequently established operant response. J Exp Psychol 38: 173-177.

Everitt BJ, Cardinal RN, Parkinson JA, Robbins TW. 2003. Appetitive behavior: Impact of amygdala-dependent mechanisms of emotional learning. Ann N Y Acad Sci 985: 233-250.

Gallagher M, Graham PW, Holland PC. 1990. The amygdala central nucleus and appetitive Pavlovian conditioning: Lesions impair one class of conditioned behavior. J Neurosci 10: 1906-1911.

Goosens KA, Maren S. 2001. Contextual and auditory fear conditioning are mediated by the lateral, basal, and central amygdaloid nuclei in rats. Learn Mem 8: 148-155.

Gross CT, Canteras NS. 2012. The many paths to fear. Nat Rev Neurosci 13: 651-658.

Hatfield T, Han JS, Conley M, Gallagher M, Holland P. 1996. Neurotoxic lesions of basolateral, but not central, amygdala interfere with Pavlovian second-order conditioning and reinforcer devaluation effects. J Neurosci 16: 5256-5265.

Holland PC, Petrovich GD, Gallagher M. 2002. The effects of amygdala lesions on conditioned stimulus-potentiated eating in rats. Physiol Behav 76: 117-129.

Kita H, Kitai ST. 1990. Amygdaloid projections to the frontal cortex and the striatum in the rat. J Comp Neurol 298: 40-49.

Koya E, Golden SA, Harvey BK, Guez-Barber DH, Berkow A, Simmons DE, Bossert JM, Nair SG, Uejima JL, Marin MT, et al. 2009. Targeted disruption of cocaine-activated nucleus accumbens neurons prevents context-specific sensitization. Nat Neurosci 12: $1069-1073$.

LeDoux JE. 2012. Rethinking the emotional brain. Neuron 73: 653-676.

LeDoux JE, Cicchetti P, Xagoraris A, Romanski LM. 1990. The lateral amygdaloid nucleus: Sensory interface of the amygdala in fear conditioning. J Neurosci 10: 1062-1069.
Lee HJ, Groshek F, Petrovich GD, Cantalini JP, Gallagher M, Holland PC. 2005. Role of amygdalo-nigral circuitry in conditioning of a visual stimulus paired with food. J Neurosci 25: 3881-3888.

Lee HJ, Gallagher M, Holland PC. 2010. The central amygdala projection to the substantia nigra reflects prediction error information in appetitive conditioning. Learn Mem 17: 531-539.

Maren S. 2005. Synaptic mechanisms of associative memory in the amygdala. Neuron 47: 783-786.

McDonald AJ. 1998. Cortical pathways to the mammalian amygdala. Prog Neurobiol 55: 257-332.

Paré D, Quirk GJ, LeDoux JE. 2004. New vistas on amygdala networks in conditioned fear. J Neurophysiol 92: 1-9.

Parkinson JA, Robbins TW, Everitt BJ. 2000. Dissociable roles of the central and basolateral amygdala in appetitive emotional learning. Eur J Neurosci 12: 405-413.

Petrovich GD, Ross CA, Mody P, Holland PC, Gallagher M. 2009. Central, but not basolateral, amygdala is critical for control of feeding by aversive learned cues. I Neurosci 29: 15205-15212.

Pickens CL, Saddoris MP, Setlow B, Gallagher M, Holland PC, Schoenbaum G. 2003. Different roles for orbitofrontal cortex and basolateral amygdala in a reinforcer devaluation task. J Neurosci 23: 11078-11084.

Piette CE, Baez-Santiago MA, Reid EE, Katz DB, Moran A. 2012. Inactivation of basolateral amygdala specifically eliminates palatability-related information in cortical sensory responses. J Neurosci 32: 9981-9991.

Prévost C, Liljeholm M, Tyszka JM, O’Doherty JP. 2012. Neural correlates of specific and general Pavlovian-to-instrumental transfer within human amygdalar subregions: A high-resolution fMRI study. J Neurosci 32: $8383-8390$.

Radulovic J, Kammermeier J, Spiess J. 1998. Relationship between fos production and classical fear conditioning: Effects of novelty, latent inhibition, and unconditioned stimulus preexposure. J Neurosci 18: $7452-7461$

Savander V, Go CG, LeDoux JE, Pitkänen A. 1995. Intrinsic connections of the rat amygdaloid complex: Projections originating in the basal nucleus. J Comp Neurol 361: 345-368.

Schoenbaum G, Chiba AA, Gallagher M. 1998. Orbitofrontal cortex and basolateral amygdala encode expected outcomes during learning. Nat Neurosci 1: 155-159.

Setlow B, Gallagher M, Holland PC. 2002. The basolateral complex of the amygdala is necessary for acquisition but not expression of CS motivational value in appetitive Pavlovian second-order conditioning. Eur J Neurosci 15: 1841-1853.

Sigurdsson T, Doyère V, Cain CK, LeDoux JE. 2007. Long-term potentiation in the amygdala: A cellular mechanism of fear learning and memory. Neuropharmacology 52: 215-227.

Swanson LW. 2004. Brain maps: Structure of the rat brain. Elsevier, Amsterdam.

Swanson LW, Petrovich GD. 1998. What is the amygdala? Trends Neurosci 21: $323-331$.

Weingarten HP. 1983. Conditioned cues elicit feeding in sated rats: A role for learning in meal initiation. Science 220: $431-433$.

Wilensky AE, Schafe GE, Kristensen MP, LeDoux JE. 2006. Rethinking the fear circuit: The central nucleus of the amygdala is required for the acquisition, consolidation, and expression of Pavlovian fear conditioning. J Neurosci 26: 12387-12396.

Received March 11, 2013; accepted in revised form March 28, 2013. 


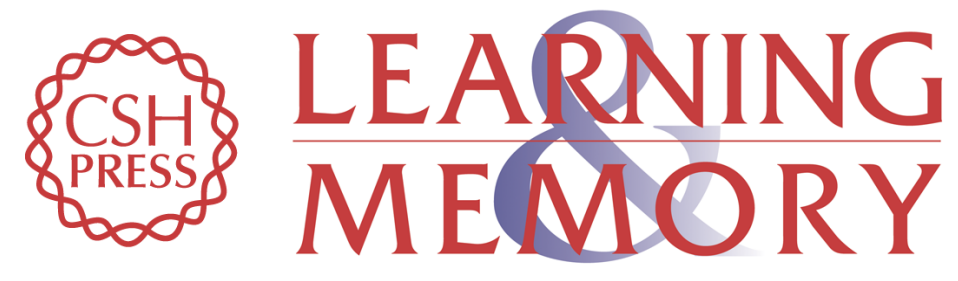

\section{Differential recruitment of distinct amygdalar nuclei across appetitive associative learning}

Sindy Cole, Daniel J. Powell and Gorica D. Petrovich

Learn. Mem. 2013, 20:

Access the most recent version at doi:10.1101/Im.031070.113

Supplemental http://learnmem.cshlp.org/content/suppl/2013/05/14/20.6.295.DC1
Material

References This article cites 35 articles, 14 of which can be accessed free at: http://learnmem.cshlp.org/content/20/6/295.full.html\#ref-list-1

License

Email Alerting Receive free email alerts when new articles cite this article - sign up in the box at the Service top right corner of the article or click here. 